\title{
Physical Performance and the Relationship to Game Performance in Elite
}

\section{Adolescent Ice Hockey: A Case}

\section{Study}

Markus N. C. Williams ${ }^{1}$ and Stefan Graua ${ }^{2}$

${ }^{1}$ Department of Food and Nutrition, and Sport Science, University of Gothenburg, Gothenburg, Sweden; ${ }^{2}$ Center for Health and Performance at the University of Gothenburg, Gothenburg, Sweden

\section{ABSTRACT}

Determining performance indicators within team sports is considerably important as it facilitates the underlying training methodologies of sports performance. The value of understanding individual contribution and the relevant physical factors is of importance when structuring appropriate strength and conditioning training. Therefore, the aim of this study was to analyse the relationships between physical performance and game performance, as well as examining the relationships of physical performance and game performance dependent on competition level. This research project was a case study conducted with a team's game performance measured across a full season. Twelve elite adolescent male ice hockey players (17.92 \pm 0.9 years, $185 \pm$ $8.45 \mathrm{~cm}, 83.17 \pm 8.61 \mathrm{~kg}$ ) participated in the study after giving informed consent. Physical performance was measured using four tests (horizontal jump, single-leg lateral jump, 15-meter sprint, corner $S$ test), while game performance was calculated through the statistical equation Point Shares. Statistical significance was set at $p \leq 0.05$. Physical performance did not depict any strong indications of overall game performance. Instead, results illustrated an inverse relationship between plyometric performance and offensive point shares. However, corner S test - nondominant may be a relevant indicator of defensive game performance dependent on competition level (high; $r=-0.618$, low; $r=-0.334)$. Given the results mostly exhibited non-significant correlations ( $p>$ $0.05)$, the findings suggest that explaining individual performance within team sports is a highly complex issue that needs further investigation.

Keywords: ice hockey; physical performance; game performance; key performance indicators; team sports. 


\section{Introduction}

Sports practitioners are continuously incorporating new strategies and methods to improve their probability of success. In team sports, the ability to precisely measure individual contribution is highly sought after and still developing $(6,23)$. However, the ability to accurately measure performance indicators in open-skilled sports is often compromised into rough estimations due to the plethora of factors that influence game performance outcome (23). Nonetheless, explaining game performance is largely the basis of understanding which variables are performance indicators among individual athletes in team sports (23). Therefore, it is crucial to estimate the game performance as precisely as possible in order to identify the variables differentiating the athletes, with the aim to develop new performance enhancement strategies.

The sport of ice hockey consists of intermittent high-intensity bouts with powerful collisions throughout the game (4). Regular gameplay at even line-ups includes five skaters and one goaltender on the ice for each team. The rink is $60 \times 30$ meters (10), but the gameplay is often condensed into one of the three similarsized zones generating ongoing oppositional encounters and agility. Elite ice hockey players' physical performance standards have been explained by aerobic, anaerobic and strength variables $(1,711$, 21). In detail, physical tests considering repeated sprint ability $(1,21)$, bench press $(1,21)$, maximal oxygen uptake $(7,21)$ and vertical jump $(1,11)$ have commonly been researched in the literature. These studies have often implemented methods of assessing individual game performance not necessarily relating to true performance outcome (i.e. contribution to team performance). Therefore, general conclusions are difficult to draw from the current literature as to which variables may best explain individual game performance. Additionally, studies have analysed the same independent variables but reached contradictive results $(7,21)$, which highlights the undesirable effect of differentiating assessment methods of individual game performance. A general observation-based model titled "Team Sport Assessment Procedure" was applied to ice hockey but was later deemed to be unstable due to interrater reliability (19). Further detail into an objective assessment method of individual game performance may elicit results that prove to be homogenous among different populations of elite ice hockey players, resulting in rational conclusions to be drawn. The emergence of data analytics in team sports, including ice hockey, have led to more advanced objective metrics regarding the assessment of individual performance in a team environment (18, 20, 25). Using a Point Share (PS) system, see Figure 1 , to analyse the individual performance has been well documented $(3,20)$ and may currently provide the most accurate estimation of player contribution in ice hockey.

$$
\begin{aligned}
\text { Point Shares }= & (M G \div M G P P)+(M G A \div \\
& \text { MGPP })
\end{aligned}
$$

Figure 1. Point Share equation (14). MG = Marginal goals, MGPP = Marginal goals per point, MGA = Marginal goals against

Coinciding with previous literature $(1,2,7$, $13,21,22,24,26)$ this study will focus on physical variables and their relation to game performance. The aim of this study is twofold. One, analyse the relationships between physical performance and game performance. Two, examine the 
relationships between physical performance and game performance based on competition level. This study will complement the current literature surrounding sports performance in ice hockey. The research questions are specified accordingly, is there a relationship between physical performance variables and game performance variables (1) on the individual level and (2) dependent on competition level.

\section{METHODS}

\section{Experimental Design}

Table 1. Game performance variables.

\begin{tabular}{ll}
\multicolumn{1}{c}{ Variable } & \multicolumn{1}{c}{ Description } \\
\hline Offensive point share (OPS) & $\begin{array}{l}\text { Share of individual's offensive contribution in terms of team } \\
\text { points. } \\
\text { Share of individual's defensive contribution in terms of team } \\
\text { points. } \\
\text { The total share of an individual's contribution in terms of } \\
\text { team points. }\end{array}$ \\
Point share (PS) & $\begin{array}{l}\text { Percentage of individual's contribution in terms of team } \\
\text { points in relation to the team's total points. } \\
\text { Relative point share (PS\%) }\end{array}$ \\
Point share per individual's contribution in terms of team points per \\
game played.
\end{tabular}

Table 2. Physical performance variables.

\begin{tabular}{|c|c|}
\hline Variable & Description \\
\hline Horizontal jump (HJ) & Bilateral jump for maximal distance. \\
\hline Single-leg lateral jump - Dominant (SLL-D) & $\begin{array}{l}\text { Unilateral jump in the medial direction for maximal distance, the best } \\
\text { performance of the leg with the furthest distance. }\end{array}$ \\
\hline Single-leg lateral jump - Non-dominant (SLL-ND) & $\begin{array}{l}\text { Unilateral jump in the medial direction for maximal distance, the best } \\
\text { performance of the leg with the nearest distance. }\end{array}$ \\
\hline Single-leg lateral jump - Asymmetry (SLL-A) & $\begin{array}{l}\text { Percental difference between dominant and non-dominant leg in the singe- } \\
\text { leg lateral jump. }\end{array}$ \\
\hline $15 \mathrm{~m}$ Sprint & A 15-meter linear skating sprint in forwarding direction. \\
\hline Cornering S test - Dominant (CST-D) & $\begin{array}{l}\text { An agility skating course including an S-shaped turn, the best performance of } \\
\text { the fastest directional start. }\end{array}$ \\
\hline Cornering S test - Non-dominant (CST-ND) & $\begin{array}{l}\text { An agility skating course including an S-shaped turn, the best performance of } \\
\text { the slowest directional start. }\end{array}$ \\
\hline Cornering S test - Asymmetry (CST-A) & $\begin{array}{l}\text { Percental difference between dominant and non-dominant directional starts } \\
\text { in the cornering } \mathrm{S} \text { test. }\end{array}$ \\
\hline
\end{tabular}

This study is a cross-sectional case study of an elite youth ice hockey team. The study involved two types of performance measurements, game performance and physical performance. Game performance was based on statistics from all 45 regularseason games, with 18 games deriving from a higher competition level (elite national league) and the remaining 27 games deriving from a lower competition level (elite regional league). Official game reports were retrieved from the leagues' official website and consequently filtered into the relevant game statistics. See Table 1 for the complete list of game performance variables. 
Individual game performance was assessed by applying the Point Share system, which takes the individual contribution of team performance into account when assessing player performance $(3,20)$. The system considers both offensive and defensive contribution, which minimises the differences between positional game demands.

Physical performance was assessed by using four tests, comprising of two skating tests and two plyometric tests: horizontal jump, single-leg lateral jump, 15-meter sprint and cornering $S$ test. In cases where lateral differences were tested, both lateral-dominance and asymmetry were recorded and thereby resulting in a total of eight physical performance variables, see Table 2.

\section{Subjects}

The study's sample included twelve adolescent elite male ice hockey players $(17.92 \pm 0.9$ years, $185 \pm 8.45 \mathrm{~cm}, 83.17 \pm$ $8.61 \mathrm{~kg})$. All participants were players from a single team competing in the elite national youth league and consisted of both defensemen $(n=5)$ and forwards ( $n=$ 7). Goaltenders were excluded from the study due to their vastly differentiating game demands. Players needed to have played in at least half of the season's games to be eligible to participate in the study. The study was conducted according to the declaration of Helsinki. Furthermore, the ethical guidelines outlined by the national research council were all adhered to.

\section{Procedures}

The four tests were scheduled in midseason to determine the physical performance of the participants. Testing was carried out in the morning in field-test conditions due to the necessity of an ice rink. Participants were instructed to wear standard athletic attire when performing the off-ice tests and wearing full ice hockey gear including helmet and stick for the onice tests to replicate game conditions. A standardised 15-minute incremental warm-up was performed on stationary bicycles (Lifecycle GX, Life Fitness, USA), followed by five minutes of individual preparation ahead of testing. The tests were then completed in the following order.

\section{-Horizontal jump}

Starting at a designated line and landing on both feet, participants were instructed to jump horizontally with a self-determined degree of countermovement and free arm swing. The performance was then recorded using measuring tape from the designated line to the nearest heel. Participants were given two attempts with a minimum of two minutes of recovery in between jumps. If a participant skid when landing, the attempt was disqualified, and an additional attempt was given.

\section{-Single-leg lateral jump}

Although the single-leg lateral jump has not been directly tested in relating studies, research indicates unilateral tests may be more appropriate for ice hockey due to skating kinematics (9). Thus, the procedure followed the test outlines as described by Lockie et al. (16). The conditions were similar to the horizontal jump test, with slight differences. The participants began adjacent to the designated line on a single leg, then proceeded to jump inwards with free arm swing and landing on both feet. 
The distance was measured from the designated line to the closest point of the foot. Participants were given two attempts for each leg, alternating legs for each jump.

\section{-15-meter sprint}

At first, the participants were given five minutes of free skating to prepare for maximum effort sprints. Two sets of photocell timing gates (TCi Timing System, Brower Timing Systems, USA) were placed at hip height 15 meters apart on the ice with a marked line 0.5 meters in front of the first gate where the participant would begin. The sprint distance for this study's testing was set at 15 meters to match recently observed match-play characteristics (15). Participants were instructed to start in a "v-stance" with their heels touching, as well as maintaining ice contact with the stick throughout the sprint. Participants were given two attempts with a minimum of two minutes of recovery.

\section{-Cornering S test}

The cornering $\mathrm{S}$ test has been used within ice hockey research to assess skating agility on multiple occasions $(5,11)$. Alike aforementioned studies, cornering $\mathrm{S}$ test was performed per the outlines provided by Greer, Serfass, Picconatto and Blatherwick (8), only with a few modifications. Participants used the same starting position as the previous test and were instructed to keep ice contact with the stick when passing through the timing gates. Furthermore, skating was always performed forwards and was done starting in opposite directions. Thus, resulting in two attempts for each direction with a minimum of two minutes of recovery in between attempts.

\section{Statistical analysis}

Both descriptive and inferential statistics were used to analyse the variables using SPSS (SPSS Statistics 25, IBM, USA). Data distribution was assessed using the Shapiro-Wilk test of normality, which resulted in all variables exhibiting normal distribution. The statistical significance level was set at $p \leq 0.05$.

\section{-On the individual level}

At first, mean values and standard deviations (SD) for all variables on the individual level were established. Pearson correlation was then used to determine the bi-factorial relationships between the physical performance variables and game performance variables.

\section{-Dependent on the competition level}

Two categories were formed dependent on competition level. The categories were derivatives of the two main leagues the team participated in throughout the season. The lower competition level featured 27 games, while the higher competition level included 18 games. Numerical variables' relationships were then analysed using the Pearson correlation for the respective competition level. Lastly, the two competition levels' correlation results were compared and analysed.

\section{Results}

Relationship between physical performance variables and game performance variables

-On the individual level 
Descriptive statistics of physical performance and game performance were determined for the individuals and are presented in Table 3.

Only one pair of variables demonstrated statistical significance $(p=0.031)$, SLLJ-D negatively correlated with OPS $(r=$ -0.622), thereby displaying a decrease in offensive contribution as the lateral jump distance of the dominant leg was greater. All but two variable pairings of plyometric performance and individual game performance (HJ \& DPS, SLLJ-ND \& DPS) resulted in weak to strong negative relationships. See Table 4 for the full results of the relationships on physical performance and game performance.

Table 3. Descriptive statistics for individuals $(n=12)$.

\begin{tabular}{|c|c|}
\hline Variable & Mean \pm SD \\
\hline Horizontal Jump (cm) & $271 \pm 14$ \\
\hline Single-leg lateral jump - Dominant $(\mathrm{cm})$ & $215 \pm 10$ \\
\hline Single-leg lateral jump - Non-dominant $(\mathrm{cm})$ & $210 \pm 10$ \\
\hline Single-leg lateral jump - Asymmetry (\%) & $2.53 \pm 1.88$ \\
\hline $15 \mathrm{~m}$ Sprint (s) & $2.70 \pm 0.13$ \\
\hline Cornering S test - Dominant (s) & $8.64 \pm 0.16$ \\
\hline Cornering S test - Non-dominant (s) & $8.83 \pm 0.18$ \\
\hline Cornering S test - Asymmetry (\%) & $-2.08 \pm 1.13$ \\
\hline Offensive point share (au) & $0.59 \pm 3.16$ \\
\hline Defensive point share (au) & $0.97 \pm 1.80$ \\
\hline Point share (au) & $1.56 \pm 3.93$ \\
\hline Relative point share (\%) & $1.52 \pm 3.86$ \\
\hline Point share per game (au) & $0.04 \pm 0.10$ \\
\hline
\end{tabular}

Table 4. Correlation matrix between physical performance and individual game performance $(n=12)$.

\begin{tabular}{lcccccccc}
\hline & SLLJ-D & SLLJ-ND & SLLJ-A & HJ & $15 m$ Sprint & CST-D & CST-ND & CST-A \\
\hline OPS & $-0.622^{*}$ & -0.526 & -0.148 & -0.328 & -0.188 & 0.039 & -0.074 & 0.190 \\
DPS & -0.116 & 0.045 & -0.423 & 0.078 & -0.450 & -0.421 & -0.478 & 0.162 \\
PS & -0.552 & -0.402 & -0.312 & -0.228 & -0.356 & -0.161 & -0.277 & 0.227 \\
PS\% & -0.552 & -0.402 & -0.313 & -0.228 & -0.356 & -0.161 & -0.277 & 0.227 \\
PS/g & -0.572 & -0.422 & -0.306 & -0.225 & -0.324 & -0.107 & -0.237 & 0.243
\end{tabular}

Note. ${ }^{*}=$ Significant at the 0.05. SLLJ-D = Single-leg lateral jump - Dominant, SLLJ-ND = Single-leg lateral jump Non-dominant, SLLJ-A = Single-leg lateral jump - Asymmetry, HJ = Horizontal jump, CST-D = Cornering S test Dominant, CST-ND = Cornering S test - Non-dominant, CST-A = Cornering S test - Asymmetry, OPS = Offensive point share, $D P S=$ Defensive point share, $P S=$ Point share, $P S \%=$ Relative point share, $P S / g=$ Point share per game. 
Table 5. Relationships between physical performance and game performance dependent on competition level being either higher or lower.

\begin{tabular}{|c|c|c|c|c|c|c|c|c|c|c|c|c|c|c|c|c|}
\hline & \multicolumn{2}{|c|}{ SLL-D } & \multicolumn{2}{|c|}{ SLL-ND } & \multicolumn{2}{|c|}{ SLL-A } & \multicolumn{2}{|c|}{$\mathrm{HJ}$} & \multicolumn{2}{|c|}{$15 \mathrm{~m}$ Sprint } & \multicolumn{2}{|c|}{ CST-D } & \multicolumn{2}{|c|}{ CST-ND } & \multicolumn{2}{|c|}{ CST-A } \\
\hline & $\mathrm{H}$ & $\mathrm{L}$ & $\mathrm{H}$ & L & H & $\mathrm{L}$ & H & $\mathrm{L}$ & $\mathrm{H}$ & $\mathrm{L}$ & $\mathrm{H}$ & $\mathrm{L}$ & $\mathrm{H}$ & $\mathrm{L}$ & H & $\mathrm{L}$ \\
\hline OPS & $-0.647^{*}$ & -0.535 & $-0.585^{*}$ & -0.408 & -0.049 & -0.249 & -0.347 & -0.275 & -0.146 & -0.219 & 0.129 & -0.069 & -0.001 & -0.152 & 0.207 & 0.152 \\
\hline DPS & -0.068 & -0.116 & -0.147 & 0.120 & 0.209 & $0.623^{*}$ & 0.203 & 0.186 & -0.352 & -0.414 & -0.298 & -0.401 & $-0.618^{*}$ & -0.334 & $0.609^{*}$ & -0.059 \\
\hline PS & $-0.640^{*}$ & -0.400 & $-0.607^{*}$ & -0.184 & 0.022 & -0.518 & -0.399 & -0.062 & -0.256 & -0.377 & 0.024 & -0.277 & -0.206 & -0.289 & 0.400 & 0.060 \\
\hline PS\% & $-0.640^{*}$ & -0.400 & $-0.607^{*}$ & -0.184 & 0.022 & -0.519 & -0.399 & -0.062 & -0.256 & -0.377 & 0.024 & -0.277 & -0.206 & -0.289 & 0.400 & 0.060 \\
\hline PS/g & $-0.635^{*}$ & -0.425 & $-0.584^{*}$ & -0.210 & -0.028 & -0.359 & -0.359 & -0.510 & -0.199 & -0.066 & 0.115 & -0.365 & -0.105 & -0.255 & 0.371 & -0.286 \\
\hline $\begin{array}{l}\text { jump } \\
\text { test - } \\
\text { Offer }\end{array}$ & - Domina & $\begin{array}{l}\text { ant, CS } \\
\text { int sha } \\
\text { me. }\end{array}$ & are, DPS & $=$ Defe & ensive & oint st & $\begin{array}{l}\text { on-dom } \\
\text { hare, } P\end{array}$ & $\begin{array}{l}\text { ninant, } \\
S=P o i\end{array}$ & int sha & $\begin{array}{l}A=\text { Cor } \\
\text { are, } P S\end{array}$ & $\begin{array}{l}\text { nering } \\
\%=\operatorname{Re}\end{array}$ & $\begin{array}{l}\text { Stes } \\
\text { lative }\end{array}$ & $\begin{array}{l}\text { - Asym } \\
\text { point sh }\end{array}$ & $\begin{array}{l}\text { metry } \\
\text { are, } \mathrm{P}\end{array}$ & $\begin{array}{l}\text { OPS = } \\
/ g=P\end{array}$ & ing $\mathrm{S}$ \\
\hline
\end{tabular}

\section{Dependent on competition level}

The difference in the level of competition resulted in different variables correlating with IGP. Only SLL-A exhibited a significant relationship to a game performance variable within a lower level of competition, in this case, DPS ( $r=-0.623)$. However, in the higher level of competition SLLJ-D and SLLJ-ND significantly correlated with OPS, PS, PS\% and PS/g. Furthermore, DPS in the higher level of competition was significantly correlated to CST-ND ( $r=-0.618)$ and CST$A(r=0.609)$. See Table 5 for the full results of the relationships dependent on competition level.

\section{DISCUSSION}

The aim of this study was to analyse the relationships between physical performance and game performance, as well as examining the relationships of physical performance and game performance relationships based on competition level within ice hockey. The main findings in this study involve the nonindicative nature of physical testing in relation to the individuals' contribution to team performance. Furthermore, no evident discriminatory indications were demonstrated in regard to physical performance relating to game performance. Thus, highlighting the complex issues when testing physical performance with the purpose of developing key performance indicators. Consequently, strength and conditioning practitioners may benefit from extracting important game-related actions and structure training accordingly.

\section{Performance relationships on the individual level}

The study's results showed that there was only one apparent significant correlation among the tested physical variables and seasonal game performance variables, SLLI-D and OPS. However, the correlation suggested a negatively performance-based relationship that illustrated a decrease in offensive game contribution as the lateral jump increased in length. This may be due to the data collection taking place in the middle of the in-season, likely causing ice hockey players to experience greater levels of fatigue and, subsequently, 
underperforming during the physical performance tests (28). The remaining plyometric variables resulted in nonsignificant relationships which diminishes the probability of plyometric variables as performance indicators. Furthermore, multiple studies have been consistent with not finding significant correlations between plyometric performance and ice hockey performance $(2,24,26,27)$. Thus, reaffirming that plyometric testing may not indicate ice hockey performance. Consequently, strength testing may elicit stronger relationships to game performance than plyometric testing, which has been evident through significantly correlating lower body strength and ice hockey performance (21).

Although on-ice sprinting was not found to strongly correlate with any of the individual game performance variables in this study, previous studies have exhibited both an explanatory relationship (24) and a non-explanatory relationship (21) with on-ice sprinting. However, the length of the sprint in the correlating relationship was set at 30 meters (24), which is twice the length of the sprint tested in this study. Furthermore, the measurement of game performance was distinctly different. Specifically, this study measured game performance using point shares (i.e. contribution), whereas previous studies have considered variables such as plus/minus statistics $(1,21)$, individual points (1), net scoring chances and minutes (7) Thus, comparisons are difficult to draw as the differences in assessing game performance result in different capacities being evaluated.
Performance relationships dependent on competition level

When comparing performance relationships between the higher and lower competition level, far more statistically significant relationships were apparent in the higher competition level. On-ice agility and lateral plyometrics were the two strongest indicators of performance relationships dependent on competition level. The two physical abilities both place an emphasis on singleleg power, which has been hypothesised to be highly relevant for ice hockey performance (9). Nonetheless, the results revealed that lateral plyometrics indicated a negative performance-related relationship dependent on competition level.

On-ice agility was depicted as a relevant factor when the competition level is higher and may indicate a physical capacity related to defensive contribution. Theoretically, foundational abilities may become successively homogenous as the competition level equalises between oppositions, prompting skating agility as an important factor of game performance. Skating agility's importance is further supported by previous research reporting the significance of winning one-on-one situations in relation to game performance outcome (12), where skating agility would be highly beneficial. Therefore, strength and conditioning practitioners should emphasise exercises that develop an ice hockey player's multiplanar efficiency in acceleration and deceleration movements. By doing so, players may be better prepared to execute the high-intensity change-of-directions required in games (4). 


\section{Limitations}

The use of Point Shares as the foundational game performance variable may also be questioned. Although PS does take defensive contribution into deliberation, which considerably equalises statistical performance assessments across player positions, it is like many other game performance variables in the sense that it has not been validated to precisely assess game performance. It can be argued that the same lack of construct validity is the case for all the game performance variables that were found in previous research $(7,21,22,27)$. In turn, highlighting the difficulty of objectively evaluating an all-encompassing game performance variable.

The individual sample group participating in this study consisted of twelve players from one team, this equated to a large majority of available players per the inclusion criteria. Nonetheless, in comparison to similar studies $(1,7,21,26)$ this study's sample size was somewhat smaller. Effectively, there were players who were unavailable to participate and therefore resulted in a less than desirable sample size.

\section{Future recommendations}

Performance-related research in ice hockey will benefit if more attention is directed towards testing on-ice variables. Further inclusion of on-ice testing may not only result in greater performance indicators but also highlight the potential discrepancies between on-ice and off-ice testing as it relates to game performance. Moreover, the objective assessment of individual game performance in ice hockey needs to be studied to establish a valid method that can be utilised in future research. It may be favourable to incorporate the relevant practitioners (e.g. sports coaches) into the research discussion, this can result in a more extensive understanding of how to objectively assess game performance. Thus, enabling researchers to convincingly justify their findings and discover patterns throughout various studies' results. As for strength and conditioning practitioners, our findings indicate that training should include exercises targeting the underlying physical factors of skating agility (e.g. acceleration and deceleration). Less of an emphasis may be given to plyometric training, which seemingly did not represent game performance to a considerable extent in our findings as well as previous $(2,24,26,27)$. Instead, attention can be directed to closed-chain exercises aiming to increase the lowerlimb lateral peak force and rate of force production, due to the conducive kinetics relating to explosive skating (17).

\section{Conclusions}

The findings of this study suggest that physical performance variables did not explain game performance in the observed case to a considerable extent. Furthermore, on-ice agility performance may predict defensive contribution between higher and lower levels of competition, but further research is necessary. Whereas off-ice plyometric performance lacked in explaining the game performance of the studied group. In closure, sports scientists and practitioners in team sports will benefit from exploring the possibilities of precise individual contribution assessment in their respective sports to further enhance the current practice. 


\section{References}

1. Boland, M., Delude, K., \& Miele, E. M. (2019). Relationship Between Physiological Off-Ice Testing, On-Ice Skating, and Game Performance in Division I Female Ice Hockey Players. The Journal of Strength \& Conditioning Research, 33(6), 1619-1628. https://journals.Iww.com/nscajscr/Abstract/2019/06000/Relationship_Betwe en_Physiological_Off_Ice.19.aspx

2. Burr, J. F., Jamnik, R. K., Baker, J., et al. (2008). Relationship of physical fitness test results and hockey playing potential in elite-level ice hockey players. Journal of strength and conditioning research, 22(5), 1535-1543. https://journals.lww.com/nscajscr/Fulltext/2008/09000/Relationship_of_Phy sical_Fitness_Test_Results_and.20.aspx

3. Chan, T. C. Y., Cho, J. A., \& Novati, D. C. (2012). Quantifying the contribution of NHL player types to team performance. Interfaces, 42(2), 131-145.

https://pubsonline.informs.org/doi/abs/10.12 87/inte.1110.0612

4. Cox, M. H., Miles, D. S., Verde, T. J., \& Rhodes, E. C. (1995). Applied physiology of ice hockey. Sports Medicine, 19(3), 184-201. https://link.springer.com/article/10.2165/000 07256-199519030-00004

5. Farlinger, C. M., Kruisselbrink, L. D., \& Fowles, J. R. (2007). Relationships to skating performance in competitive hockey players. The Journal of Strength \& Conditioning Research, 21(3), 915-922. https://journals.Iww.com/nscajscr/Abstract/2007/08000/Relationships_To_S kating_Performance_in.44.aspx

6. Gómez-Ruano, M. A. (2018). Current approaches to performance analysis in sport. Revista Internacional de Ciencias del Deporte, 14(51), 3-4.

https://www.redalyc.org/jatsRepo/710/71055 516001/71055516001.pdf

7. Green, M. R., Pivarnik, J. M., Carrier, D. P., \& Womack, C. J. (2006). Relationship between physiological profiles and on-ice performance of a national collegiate athletic association division I hockey team. Journal of strength and conditioning research, 20(1), 43-46. https://journals.lww.com/nscajscr/Abstract/2006/02000/Relationship_Betwe en_Physiological_Profiles_and.7.aspx

8. Greer, N., Serfass, R., Picconatto, W., \& Blatherwick, J. (1992). The effects of a hockeyspecific training program on performance of Bantam players. Canadian journal of sport sciences $=$ Journal Canadien des sciences du sport, 17(1), 65-69.

https://europepmc.org/article/med/1322772

9. Henriksson, T., Vescovi, J. D., FjellmanWiklund, A., \& Gilenstam, K. (2016). Laboratory- and field-based testing as predictors of skating performance in competitive-level female ice hockey. Open Access Journal of Sports Medicine, 7, 81-88. https://www.dovepress.com/laboratory--andfield-based-testing-as-predictors-of-skatingperforman-peer-reviewed-article-OAJSM

10. International Ice Hockey Federation (2018) IIHF Official Rule Book 2018-2022 (1st Edition). Retrieved from International Ice Hockey Federation website: https://www.iihf.com/IIHFMvc/media/Downlo ads/Rule\%20Book/IIHF_Official_Rule_Book_20 18_Web_v2.pdf

11. Janot, J. M., Beltz, N. M., \& Dalleck, L. D. (2015). Multiple off-ice performance variables predict on-ice skating performance in male and female division iii ice hockey players. Journal of sports science \& medicine, 14(3), 522-529.

https://www.jssm.org/hf.php?id=jssm-14522.xml

12. Huntata, M., \& Zapletalová, L. (2012). Differences in game performance parameters of winning and losing ice-hockey teams. Acta Facultatis Educationis Physicae Universitatis Comenianae, 52(1), 29-40.

https://www.fsport.uniba.sk/fileadmin/ftvs/k niznica/Acta_Facultatis_Educationis/Acta_Fac ultatis_Educationis_Physicae_Universitatis_Co menianae_2012_LII-I.pdf\#page $=29$

13. Kniffin, K. M., Howley, T., \& Bardreau, C. (2017). Putting muscle into sports analytics: strength, conditioning, and ice hockey performance. The Journal of Strength \& Conditioning Research, 31(12), 3253-3259. https://journals.Iww.com/nscajscr/Abstract/2017/12000/Putting_Muscle_Int o_Sports_Analytics_Strength,.2.aspx

14. Kubatko, J. (n.d.). Calculating Point Shares. Retrieved from Hockey-Reference website: https://www.hockeyreference.com/about/point_shares.html.

15. Lignell, E., Fransson, D., Krustrup, P., \& Mohr, M. (2018). Analysis of high-intensity skating in top-class ice hockey match-play in relation to training status and muscle damage. The Journal of Strength \& Conditioning Research, 32(5), 1303-1310.

https://cdn.journals.Iww.com/nscajscr/Abstract/2018/05000/Analysis_of_High_I ntensity_Skating_in_Top_Class.15.aspx 
16. Lockie, R. G., Callaghan, S. J., Berry, S. P., et al. (2014). Relationship between unilateral jumping ability and asymmetry on multidirectional speed in team-sport athletes. The Journal of Strength \& Conditioning Research, 28(12), 3557-3566. https://journals.Iww.com/nscajscr/Fulltext/2014/12000/Relationship_Betwe en_Unilateral_Jumping_Ability.32.aspx

17. Marino, G. W. (Ed.) (1995, July). Biomechanics of power skating: past research, future trends. Proceedings of the 13th International Symposium on Biomechanics in Sport, Ontario, Canada. Zürich, Switzerland: International Society of Biomechanics in Sports. https://ojs.ub.unikonstanz.de/cpa/article/view/2985/2830

18. Mason, D. S., \& Foster, W. M. (2007). Putting Moneyball on ice? International Journal of Sport Finance, 2(4), 206-213. http://fitpublishing.com/content/puttingmoneyball-ice-pp-206-213

19. Nadeau, L., Richard, J.-F., \& Godbout, P. (2008). The validity and reliability of a performance assessment procedure in ice hockey. Physical Education and Sport Pedagogy, 13(1), 65-83. https://www.annualreviews.org/doi/abs/10.1 146/annurev-statistics-030718-105202

20. Nandakumar, N., \& Jensen, S. T. (2019). Historical perspectives and current directions in hockey analytics. Annual Review of Statistics and Its Application, 6(1), 19-36.

https://www.annualreviews.org/doi/abs/10.1 146/annurev-statistics-030718-105202

21. Peyer, K. L., Pivarnik, J. M., Eisenmann, J. C., \& Vorkapich, M. (2011). Physiological characteristics of national collegiate athletic association division I ice hockey players and their relation to game performance. The Journal of Strength \& Conditioning Research, 25(5), 1183-1192.

https://journals.lww.com/nscajscr/Fulltext/2011/05000/Physiological_Chara cteristics_of_National.1.aspx

22. Poltavski, D., \& Biberdorf, D. (2015). The role of visual perception measures used in sports vision programmes in predicting actual game performance in Division I collegiate hockey players. Journal of Sports Sciences, 33(6), 597608.

https://www.tandfonline.com/doi/abs/10.108 0/02640414.2014.951952

23. Robertson, S., Gupta, R., \& McIntosh, S. (2016). A method to assess the influence of individual player performance distribution on match outcome in team sports. Journal of Sports Sciences, 34(19), 1893-1900. https://www.tandfonline.com/doi/abs/10.108 0/02640414.2016.1142106

24. Roczniok, R., Stanula, A., Maszczyk, A., et al. (2016). Physiological, physical and on-ice performance criteria for selection of elite ice hockey teams. Biology of Sport, 33(1), 43-48. https://www.termedia.pl/Physiologicalphysical-and-on-ice-performance-criteria-forselection-of-elite-ice-hockeyteams,78,26644,0,1.html

25. Schumaker, R. P., Solieman, O. K., \& Chen, H. (2010). Sports knowledge management and data mining. Annual Rev. Info. Sci \& Technol., 44(1), 115-157.

26. Stanula, A. J., Roczniok, R. K., Gabrys, T. T., Szmatlan-Gabrys, U. B., \& Ozimek, M. J. (Eds.) (2018, May). Relationships of physical fitness test results and player performance indicators in national-level ice hockey players.

Proceedings of the International Scientific Conference Volume IV "Society, Integration, Education - SIE2018", Rezkne, Latvia. Rezkne, Latvia: Rezekne Academy of Technologies. http://journals.rta.Iv/index.php/SIE/article/vie $w / 3265$

27. Vescovi, J. D., Murray, T. M., Fiala, K. A., \& VanHeest, J. L. (2006). Off-ice performance and draft status of elite ice hockey players. International Journal of Sports Physiology and Performance, 1(3), 207-221.

https://journals.humankinetics.com/view/jour nals/ijspp/1/3/article-p207.xml

28. Whitehead, P., Conners, R. \& Shimizu, T. (2019). The Effect of In-Season Demands on Lower-Body Power and Fatigue in Male Collegiate Hockey Players. Journal of Strength and Conditioning Research, 33(4), 1035-1042. https://cdn.journals.Iww.com/nscajscr/Abstract/2019/04000/The_Effect_of_In_S eason_Demands_on_Lower_Body.16.aspx 